\title{
A INTERCULTURALIDADE CRÍTICA COMO ALTERNATIVA PARA UMA EDUCAÇÃO CRÍTICA E DECOLONIAL
}

\section{CRITICAL INTERCULTURALITY AS ANALTERNATIVE FOR CRITICAL AND DECOLONIAL EDUCATION}

\author{
Kellyane Lisboa Ramos \\ Pedagoga da Escola Estadual Benedito Gumercindo de Souza da Secretaria de Estado de Educação, \\ Borba, Amazonas - Brasil \\ kelly anne.ped@gmail.com \\ Eulina Maria Leite Nogueira \\ Doutora em Educação: Currículo pela Pontifícia Universidade Católica de São Paulo \\ Professora da Universidade Federal do Amazonas, Humaitá, Brasil \\ eulinanog@hotmail.com \\ Zilda Gláucia Elias Franco \\ Doutora em Educação: Currículo pela Pontifícia Universidade Católica de São Paulo \\ Professora da Universidade Federal do Amazonas, Humaitá - Brasil \\ zildaglaucia@ufam.edu.br
}

\begin{abstract}
Resumo: O objetivo deste artigo foi explicitar, com base em uma abordagem de pesquisa bibliográfica e crítica, a construção do termo "intercultural" e sua importância para uma educação crítica e decolonial. Teve-se em vista a seguinte problemática: diante das diversas discussões sobre a diversidade cultural, a formação inicial do professor pode favorecer a valoriz ação dos mais diversos conhecimentos culturais? Considera-se que, a despeito das discussões em torno da diversidade cultural, as culturas diversas ainda vivenciam desafios em relação ao reconhecimento e ao respeito às suas diferenças e especificidades. Para que ocorra a construção crítica da realidade, é mister que se tenha uma educação pautada na valorização da cultura, partindo, a priori, da decolonização do conhecimento, na perspectiva da interculturalidade crítica, como um projeto contrahegemônico. Assim sendo, ap onta-se, nas conclusões, a necessidade de decolonizar-se o conhecimento no ambiente acadêmico, no Ensino Superior, especificamente na formação inicial de professores, a fim de que estes possam construir uma prática docente que contribua para um ensino crítico e emancipador em relação às questões culturais de diversidade. Nessa construção, a interculturalidade crítica tem se demonstrado como possibilidade para promover a emancipação crítica do indivíduo, por ser uma proposta de educação política, a qual envolve uma concepção de ensino que possa contribuir para a transformação social, o que pode repercutir em uma sociedade com menos desigualdades e preconceitos.
\end{abstract}

Palavras-chave: Interculturalidade crítica. Decolonialidade. Educação crítica. Contra-hegemonia.

\begin{abstract}
The aim of this paper was to explain, based on a bibliographic and critical research approach, the construction of the intercultural term and its importance for a critical and decolonial education. The following problem was considered: in view of the various discussions on cultural diversity, can initial teacher training favor the valorization of the most diverse cultural knowledge? It is considered that, despite discussions about cultural diversity, diverse cultures still experience challenges in relation to the recognition and respect for their differences and specificities. For the critical construction of reality to occur, it is necessary to have an education based on the valorization of culture, starting, a priori, from the decolonization of knowledge, in the perspective of critical interculturality, as a counter-hegemonic project. Therefore, the conclusions point to the need to decolonize knowledge in the academic environment, in Higher Education, specifically in the initial training of teachers, so that they can build a teaching practice that contributes to a critical and emancipator teaching in relation to cultural issues of diversity. In this construction, critical interculturality has been shown itself as a possibility to promote the critical emancipation of the individual, as it is a proposal for political education, which involves a conception of teaching that can contribute to social transformation, which can have repercussions in a society with less inequality and prejudice.
\end{abstract}

Keywords: Critical interculturality. Decoloniality. Critical education. Counter-hegemony.

\section{Para citar - (ABNT NBR 6023:2018)}

RAMOS, Kelly ane Lisboa; NOGUEIRA, Eulina Maria Leite; FRANCO, Zilda Gláucia. Elias. A interculturalidade crítica como alternativa para uma educação crítica e decolonial. Eccos - Revista Cientifica, São Paulo, n. 54, p. 1-10, e17339, jul./set. 2020. Disponível em: https://doi.org/10.5585/eccos.n54.17339. 


\section{Introdução}

Este texto faz parte de estudos desenvolvidos em um dos capítulos da dissertação de Mestrado intitulada A representação social dos acadêmicos de Pedagogia do IEAA-UFAM acerca da questão Indígena, defendida no início de 2020. Trata-se de um estudo de abordagem bibliográfica, cuja análises se deram a partir de uma perspectiva crítica. Um dos objetivos era explicitar a construção do termo "intercultural" e sua importância para uma educação crítica e decolonial. A problemática abordada pauta-se na seguinte inquietação: diante das diversas discussões sobre a diversidade cultural, a formação inicial do professor pode favorecer a valorização dos mais diversos conhecimentos culturais? Ao longo deste trabalho, foi possível construir uma resposta para essa questão, baseada em discussões teóricas sustentadas em autores como Walsh (2002, 2007), Quijano (2005), Dussel (2015, 2016), entre outros.

A perspectiva da interculturalidade crítica surgiu a partir do movimento póscolonialista, que se constituiu por um conjunto de correntes teóricas e analíticas, com forte implantação nos estudos culturais. A noção de interculturalidade, hoje, está presente em todas as ciências sociais que tenham em comum "[...] dar primazia teórica e política às relações desiguais entre o Norte e o Sul na explicação ou na compreensão do mundo contemporâneo" (SANTOS, 2008, p. 8).

A interculturalidade crítica surgiu a partir desse movimento; todavia, tornou-se ampla, o que implicou que outras áreas de conhecimento e correntes epistemológicas pudessem também considerá-la como uma alternativa emancipatória. Assim, esse termo passou a ser utilizado, ainda nos anos 1970 e 1980, por motivo das relações migratórias que ocorriam no continente Europeu. Tais relações eram resultantes do fluxo de imigrantes que, em decorrência de sua situação social, econômica e de guerras abandonavam seus países de origem em busca de melhores condições de vida.

A partir dessa conjuntura, os imigrantes passaram a povoar partes da Europa, o que ocasionou aumento demográfico e tornou a relação entre as diferentes culturas algo conflituoso, visto que, de acordo com Moura (2005, p. 30), “[...] o ex-colonizado, frequenta agora as ruas e praças, mercados e igrejas, escolas e cinemas"; cotidianamente, disputa vagas de emprego, submete-se à tutela do estado, que é responsável por sua saúde, pela educação de seus filhos e por sua seguridade social, trazendo consigo valores que colocam em cheque suas tradições morais como instituição familiar e monogamia.

Diante dessa nova realidade, houve a necessidade de conviver-se e tolerar as diferenças, o que se encaixa na concepção multiculturalista, uma vez que é preciso viver e conviver de 
forma pacífica. Assim, com base nesse cenário, o conceito do termo "intercultural", com viés pautado no multiculturalismo, passou a ser utilizado como forma de "aceitar" as culturas diferentes. Tal concepção vai de encontro à noção de interculturalidade crítica, a qual busca valorizar e aprender a cultura de ambas as partes, em que a identidade do outro não é só tolerada, mas respeitada, e há possibilidade de aprender e conhecer o "diferente".

Nessa esteira de pensamento, ao longo deste artigo, defendemos a ideia de que a diversidade cultural deve ser respeitada e valorizada na construção de novos conhecimentos, em uma perspectiva intercultural crítica. Desse modo, consideramos que a decolonialidade, pensada a partir da Educação Superior, poderá contribuir para uma formação de professores que corrobore para uma prática diferenciada frente às diversas realidades culturais.

\section{A interculturalidade e a cons trução de diálogos interculturais}

A expressão "diálogo intercultural", proposta por Enrique Dussel (2016), busca diferenciar o diálogo multicultural do intercultural. A noção de diálogo multicultural implica a aceitação de alguns princípios ocidentais que devem ser atendidos pela população. Assim, do ponto de vista econômico e político, as pessoas não contestam a estrutura do Estado Liberal multicultural, o que permite a institucionalização da cultura ocidental como hegemônica, subalternizando as demais culturas. Conforme Dussel (2016, p. 60), “[...] impõe-se uma estrutura cultural em nome de elementos puramente formais de convivência (que tem sido uma expressão do desenvolvimento de uma cultura particular)".

Em oposição a esse pensamento, desde 1974, tem-se desenvolvido a noção de diálogo intercultural, que vai ao encontro dos postulados multiculturalistas, acarretando uma dialogicidade ' [...] intercontinental 'Sul-Sul' entre os pensadores da África, Ásia e América Latina, cuja primeira reunião foi realizada em Dar-Es-Salaam (Tanzânia) em 1976" (DUSSEL, 2016, p. 52). A partir de então, a proposta enfatizada por Dussel é que o diálogo intercultural caminhe para o compromisso e a construção de um diálogo epistemológico que considere as diversidades. O autor sugere, ainda, que, mesmo havendo a desproporção no exercício do poder pelo Norte sobre o Sul, é necessário que as comunidades pós-coloniais possam vir a estabelecer entre si um diálogo (DUSSEL, 2015).

Nesse sentido, para que possa existir a relação de diálogo entre Norte e Sul, é preciso, inicialmente, compreender que, historicamente, a produção de conhecimento situada no Sul foi restrita ao paradigma eurocêntrico, como é o caso dos países colonizados. Devemos considerar, ainda, a dependência epistêmica a que os países do Sul foram submetidos, o que traz grandes 
desafios, pois, de acordo com Bragato (2017, n.p.), não há “[...] valorização de nossas experiências culturais, o que acaba reproduzindo modelos de conhecimento pouco responsivos aos nossos processos de constituição social, econômica, política e cultural. Somos educados a obedecer e a (mal) copiar".

Fornet-Betancourt (1994) afirma que possibilitar a construção de um diálogo intercultural torna-se "[...] a única alternativa que promete nos conduzir à superação efetiva de formas de pensar que, de uma ou outra maneira, resistem ao processo da argumentação aberta, ao condensar-se em posições dogmáticas, determinadas somente a partir de uma perspectiva monocultural” (FORNET-BETANCOURT, 1994, p. 19). Dessa maneira, o diálogo intercultural é considerado um instrumento em busca da superação contra o paradigma ocidental que vêm influenciando os países considerados em desenvolvimento, pois o projeto multicultural "[...] nega a alteridade, impõe o monologismo e não procura a dialogicidade" (MÁRQUEZFERNÁNDEZ; DE LOS RIOS, 2001, p. 279). Então, só será possível dialogarmos interculturalmente quando reconhecermos o paradigma eurocêntrico e colocarmos em pauta uma nova discussão, buscando, a partir da decolonialidade, argumentar e interpretar a realidade a partir da decolonização do conhecimento.

Contudo, antes de adentrarmos os estudos acerca da interculturalidade na perspectiva da decolonialidade, é necessário explicitarmos o paradigma eurocêntrico, a fim de deixar claro como ocorreu esse processo e como ele culminou na categorização e na divisão entre Norte e Sul.

\section{Decolonização do conhecimento como instrumento de emancipação}

Partindo do pressuposto de que o eurocentrismo expressa a racionalidade específica do padrão global de poder, estabelecido na modernidade por meio das relações coloniais (QUIJANO, 2005), o paradigma eurocêntrico trata-se de uma perspectiva binária e dualista das relações intersubjetivas e culturais entre a Europa e o resto do mundo, codificada em um conjunto de categorias (Oriente-Ocidente, primitivo-civilizado, mágico/mítico-científico, irracional-racional, tradicional-moderno) (BRAGATO, 2017).

A perspectiva eurocêntrica passou, assim, a exercer uma hegemonia, principalmente no que concerne à produção de conhecimento, causando a racialização do Ocidente, bem como do mundo. Nesse sentido, raça, classe e nação foram conceitos desenvolvidos, antes de tudo, na Europa, para ajudar na interpretação de novas relações sociais (BANTON, 1977). Isso foi alcançado por meio de dois mitos principais, fundamentados nas seguintes concepções: (i) a 
história da civilização humana é um caminho linear para o progresso, cujo apogeu é a Europa; (ii) as diferenças entre a Europa e a não-Europa são naturais e não resultantes das relações assimétricas de poder (QUIJANO, 2005).

A partir do momento que firmou sua superioridade sobre os países que viriam a ser colonizados e explorados, o paradigma eurocêntrico "[...] desumanizou seres humanos e desprezou o conhecimento e as formas de organização social e expressão cultural de outros povos" (BRAGATO, 2017, n.p.). Assim sendo, a colonialidade permanece hegemônica. A hegemonia dá-se a partir das relações estabelecidas entre questões políticas, sociais e econômicas, como também na produção de conhecimento, que desqualifica os conhecime ntos das culturas populares e considera como único e verdadeiro apenas aquele provado cientificamente.

Do ponto de vista da concepção decolonial, a busca pelo progresso e pela modernidade fortaleceu as desigualdades sociais, além da hegemonia legitimada no Sul pela colonialidade do Norte. Essa condição permanece invisível aos nossos olhos (geralmente pela maioria), acarretando um consenso que, de alguma forma, centraliza o poder no Ocidente. Conforme expõe Alves (2017, p. 56), “[...] a forma de fazer conhecimento e também as políticas de desenvolvimento no Ocidente baseou-se em pressupostos binários de classificações, e uma das mais utilizadas é a concepção teórica de moderno/tradicional: ao primeiro consiste estar no desenvolvimento e ao segundo no subdesenvolvimento".

Desse modo, a supremacia do Ocidente em relação ao restante do mundo o colocou em posição de destaque, categorizando os demais continentes como lugares a serem descobertos, colonizados e explorados. No entanto, “[...] as culturas do Sul têm sobrevivido como a alteridade que, lentamente, reaparece das cinzas do colonialismo" (DUSSEL, 2015, p. 282). Mesmo que o período colonial já tenha sido ultrapassado, isso não quer dizer que a sociedade viva em uma conjuntura social, política e cultural descolonizada. O paradigma colonial e colonialista permanece enraizado na história, e o colonialismo se manifesta, a todo momento, em uma relação de constância dialética.

O colonialismo denota uma relação política e econômica em que a soberania de uma nação ou de um povo repousa sobre o poder de outra nação, tornando-se um império (MALDONADO-TORRES, 2007). Nesse sentido, a partir das relações políticas e econômicas vinculadas ao colonialismo, emerge e permanece a colonialidade de um país sobre o outro, por meio de "[...] padrões de poder de longa data que surgiram como resultado do colonialismo, mas que definem a cultura, o trabalho, as relações intersubjetivas e a produção de conhecimento muito além dos limites rígidos das administrações colonia is" 
(MALDONADO-TORRES, 2007, p. 243). Desse modo, embora os países que um dia foram colonizados tenham sobrevivido e resistido à opressão dos colonizadores, ainda assim permanece a perspectiva da colonialidade na condição de subalternidade de grande parte da sociedade. É preciso desconstruirmos essa condição subalterna por intermédio de uma educação decolonizadora, que proporcione uma reflexão crítica da realidade, contestando, assim, o status quo.

O termo "decolonialidade" surgiu a partir das experiências da própria colonialidade, mas vinculada à ideia pós-colonial, mas “[...] não sinaliza uma simples sucessão cronológica do tipo antes/depois. Ao contrário, o "pós-colonial" marca a passagem de uma configuração ou conjuntura histórica de poder para outra” (HALL, 2003, p. 56). Logo, “[...] apesar de ser um depois, vai além do colonialismo, já que as teorias pós-coloniais se fundamentam numa atividade crítica de contestação e leitura crítica do legado colonial” (CARVALHO, 2010, p. 3). Assim, para contestar a colonialidade e propor a construção da decolonialidade, é preciso buscar estabelecer um diálogo fértil (DUSSEL, 2015), havendo a necessidade de teóricos do Sul colocar em pauta suas problemáticas, gerando discussões voltadas à reflexão, em um diálogo intercultural.

Nesse viés, a partir da perspectiva decolonial, buscamos propor uma ruptura epistemológica que nos dê possibilidades para desmitificar conhecimentos que emergiram do paradigma eurocêntrico, considerados e postulados como verdades absolutas. A proposta decolonial tem muito a oferecer e contribuir nas discussões voltadas às epistemologias do Sul, “[...] pois uma epistemologia do Sul se assenta em três orientações: aprender que existe o Sul; aprender a ir para o Sul; aprender a partir do Sul e com o Sul”' (SANTOS, 2005, p. 508).

Torna-se necessário que a decolonização do discurso hegemônico aconteça para que possa haver a construção desse diálogo, o que pode resultar em um aspecto caracterizado como transmodernidade, uma nova abordagem que se refere a ir além da modernidade, em uma construção que se dá a partir do colapso capitalista eurocêntrico e dos postulados colonialis tas. Essa nova ideia se constitui por meio de um processo pluriverso, em que as culturas diferentes estão propensas à discussão, em um diálogo criativo, possibilitando a pluriversidade, resultado de um diálogo intercultural autêntico, que deve levar claramente em conta as assimetrias de poder (DUSSEL, 2015).

É preciso continuarmos acreditando que, por meio da decolonialidade do conhecimento, iremos culminar na promoção de um projeto de ensino e de formação que esteja aberto a desmitificar pré-conceitos, na busca por esse diálogo cada vez mais necessário em um mundo carregado de estereótipos e preconceitos emergidos da colonialidade. Assim sendo, é 
imprescindível construirmos uma sociedade pautada em uma perspectiva intercultural crítica, em todas as esferas, de modo a considerar e reconhecer que todos os conhecimentos são importantes.

\section{Interculturalidade crítica: um projeto contra-hegemônico}

A interculturalidade crítica, na perspectiva de Walsh (2007), é

[...] una configuración conceptual, una ruptura epistémica que tiene como base el pasado y el presente, vividos como realidades de dominación, explotación y marginalización, que son simultáneamente constitutivas, como consecuencia de lo que Mignolo há llamado modernidad/colonialidad. (WALSH, 2007, p. 50).

Em sua concepção, a referida autora enfatiza que a interculturalidade, além de ser tratada como proposta, é também uma configuração conceitual que vai de encontro à situação social e política vivenciada pelas culturas subalternizadas pelo projeto colonizador. Então, podemos compreender que existe uma contra-hegemonia epistemológica.

Tal entendimento se deu somente a partir do momento que Walsh (2002) direcionou esse conceito para a realidade do movimento indígena no Equador. A partir da compreensão situada no centro de questionamentos vinculados à noção e à situação de poder, sobrevindas da colonialidade e das propostas imperialistas, o próprio movimento indígena passou a questionar a utilização da palavra "interculturalidade" como mais voltada aos domínios neoliberais do estado do que propriamente para uma perspectiva de mudança, em que sua cultura e saberes seriam respeitados e seus direitos garantidos.

Assim, “[...] cuando la palabra interculturalidad la emplea el Estado en el discurso oficial, el sentido es equivalente a multiculturalidad. El Estado quiere ser inclusivo, reformador, para mantener la ideología neoliberal y la primacía del mercado" (WALSH, 2002, p. 26). Nesse sentido, o discurso intercultural está atrelado às intenções do Estado de se manter no poder. Por isso, é preciso repensarmos o conceito de interculturalidade, pois este não pode ser tratado simplesmente como o entrelaçamento entre culturas tradicionais e ocidentais. Precisamos ter cautela em relação a que tipo de interculturalidade representa a diversidade, uma vez que pode estar camuflada em um discurso de respeito e aceitação, mas cuja intenção, na realidade, é somente promover a tolerância e, assim, impossibilitar uma contra-hegemonia.

Foi somente por meio do movimento indígena equatoriano que a perspectiva intercultural passou por uma ressignificação conceitual, o que caracterizou o termo não mais como um conceito inerente à realidade. O movimento indígena, no Equador, imputou à 
perspectiva intercultural uma nova conotação, agora vinculada a um projeto anti-hegemônico, que devia ser proposto e assumido, em primeiro lugar, pelos próprios indígenas e, sobretudo, a partir de práticas educacionais libertadoras, pelas demais camadas subalternizadas da sociedade brasileira (CAVALCANTE, 2017). De acordo com Walsh (2007), esse projeto intercultural crítico "[...] poderia expandir-se e abarcar uma aliança com pessoas que também buscam construir alternativas à globalização neoliberal e à racionalidade ocidental, e que lutam tanto pela transformação social como pela criação de condições de poder, saber e ser muito diferentes" (WALSH, 2007, p. 8, tradução nossa).

Para acontecer a mudança do paradigma da colonialidade para a promoção da interculturalidade crítica, é de suma importância a decolonização do conhecimento. A interculturalidade crítica é um instrumento essencial e estratégico em relação à educação, podendo possibilitar que o espaço acadêmico promova ações construtivas para que ocorra o reconhecimento e respeito às diversidades culturais existentes, além de "[...] compreender o mundo a partir de diferentes formas sócio históricas que possibilitem a reflexão sobre seu próprio contexto e sobre outras realidades, as que podem estar ou não próximas deles, em termos tanto materiais quanto simbólicos [...]” (MARTÍNEZ et al., 2009, p. 52).

$\mathrm{O}$ intercultural está atrelado à igualdade de oportunidades, de forma a reconhecer os conhecimentos e os saberes de cada cultura, promover o enriquecimento das diferenças culturais em uma perspectiva coletiva. Trata-se de um projeto em comum, o qual enfatiza que todas as culturas podem e devem ser reconhecidas em suas especificidades, cujas diferenças são integradas - e não excluídas - dentro de um aspecto social, cultural.

Dessa forma, consideramos que a interculturalidade pode constituir, no âmbito da educação, uma estratégia ética, política e epistêmica. Nessa perspectiva, os processos educativos são fundamentais. Por meio deles, podemos questionar a colonialidade presente na sociedade e na educação, desvelar o racismo e a racialização das relações (CANDAU; RUSSO, 2011). Assim sendo, apontamos a necessidade de criar-se uma proposta de currículo baseada em uma construção intercultural crítica, que proporcione debates em diferentes contextos, de modo a promover o conhecimento entre os vários campos do saber.

\section{Considerações finais}

Pensar sob o ponto de vista da interculturalidade implica atentar para o fato de que essa abordagem não está associada apenas a ações vinculadas aos povos indígenas e afrodescendentes. Com o tempo, essa concepção ampliou-se e, hoje, representa não somente 
esses grupos, mas também todas as populações que foram colonizadas, subalternizadas e excluídas. Estas buscam ser tratadas como povos que possuem culturas e conhecimentos não menos importantes do que os impostos e os legitimados pelo Ocidente.

Assim, compreendemos que promover a interculturalidade crítica nos cursos de formação inicial de professores, no currículo e na educação, pode proporcionar a construção de um projeto educacional vinculado a mudanças no campo social, como estratégia política de transformação emancipatória. A isso está interligada uma condição de crescimento e mudança de consciência; construí-la demanda, além de tempo, uma educação voltada à conscientização sobre as próprias condições históricas, em uma perspectiva crítica e dialética.

Diante disso, é preciso combater as divisões que emergiram do colonialismo e buscar proporcionar uma educação voltada ao rompimento da alienação e da omissão que perpetua a divisão entre dois ou mais tipos de saberes. É necessário colocar em prática a interculturalidade em todas as instâncias educacionais. Para que isso ocorra, de acordo com a perspectiva de ensino aqui apontada, é preciso haver a decolonização do conhecimento, para que se possa tentar romper, de algum modo, com os paradigmas de exclusão e de discriminação, tornandonos uma sociedade mais humana e ética.

\section{Referências}

ALVES, A. de B. O pós-colonialismo: por uma nova epistemologia das ciências sociais no sul. Revista de História Bilros: História(s), Sociedade(s) e Cultura(s), v. 5, n. 8, p. 50-64, 2017.

BANTON, M. A ideia de raça. Tradução Antônio Marques Bessa. São Paulo: Martins Fontes, 1977.

BRAGATO, F. F. Diálogo intercultural para um mundo pluriversal: um caminho por onde andar. Empório do Direito, São Paulo, 6 mar. 2017. Disponível em: https $/ /$ emporiododireito.com.br. Acesso em: 20 abr. 2019.

CANDAU, V. M. F. RUSSO, K. Interculturalidade e educação na América Latina: uma construção plural, original e complexa. In: CANDAU, V. M. (org.). Diferenças culturais e educação: construindo caminhos. Rio de Janeiro: 7 letras, 2011. p. 71-75.

CARVALHO, F. A. Formações identitárias no pós-colonialismo: quem é o sujeito negro? Revista Teias, Rio de Janeiro, ano 11, n. 21, p. 1-8, jan./abr. 2010.

CAVALCANTE, T. L. V. "Terra Indígena": aspectos históricos da construção e aplicação de um conceito jurídico. Revista História, São Paulo, v. 35, e75, p. 1-22, 2016. 
DUSSEL, E. Filosofías de Sur. Descolonización y Transmodernidad. Mexico, D.F.: Akal, 2015 .

DUSSEL, E. Transmodernidade e interculturalidade: interpretação a partir da filosofa da libertação. Revista Sociedade e Estado, v. 31, n. 1, p. 51-73, jan./abr. 2016.

FORNET-BETANCOURT, R. Interculturalidade: críticas, diálogo e perspectivas. Tradução Angela Tereza Sperb. São Leopoldo: Nova Harmonia, 1994.

HALL, S. Da diáspora identidades e mediações culturais. Belo Horizonte: Editora UFMG; Brasilia: Representação da UNESCO no Brasil, 2003.

MALDONADO-TORRES, N. Sobre la colonialidad del ser: contribuciones al desarrollo de un concepto. In: CASTRO-GÓMEZ, S.; GROSFOGUEL, R. (ed.). El giro decolonial. Reflexiones para una diversidad epistémica más allá del capitalismo global. Bogotá: IescoPensar-Siglo del Hombre Editores, 2007. p. 127-167.

MÁRQUEZ-FERNÁNDEZ, A.; DE LOS RÍOS, L. La filosofía del diálogo intercultural en el pensamiento de Raúl Fornet-Betancourt. Telos: Revista de Estudios Interdisciplinarios en Ciencias Sociales, Maracaíbo, v. 3, n. 3, p. 278-286, 2001.

MARTÍNEZ, M. E. et al. Políticas e práticas de educação intercultural. In: CANDAU, V. M. (org.). Educação Intercultural na América Latina: entre concepções, tensões e propostas. Rio de Janeiro: 7 letras, 2009. p. 44-72.

MOURA, M. Diversidade Cultural e democracia: breve reflexão sobre os desafios da pluralidade. Textos e Contextos, Salvador, v. 3, n. 3, p. 29-38, 2005.

QUIJANO, A. Colonialidade do poder, eurocentris mo e América Latina. In: LANDER, E. (org.). A colonialidade do saber: eurocentrismo e ciências sociais. Perspectivas latinoamericanas. Buenos Aires: Colección Sur Sur, CLACSO, 2005. p. 227-278.

SANTOS, B. de S. Do pós-moderno ao pós-colonial. E para além de um e de outro. Revista Travessias, Coimbra, v. 6/7, p. 15-36, 2008.

WALSH, C. (De)Construir la Interculturalidad: consideraciones críticas desde la política, la colonialidad y los movimentos indígenas y negros em el Ecuador. 2002. Disponível em: http://www.uasb.edu.ec/UserFiles/363/File/PonenciaLima1.pdf. Acesso em: 10 set. 2020.

WALSH, C. Interculturalidad y colonialidad del poder. Un pensamiento y posicionamiento "otro" desde la diferencia colonial. In: CASTRO-GÓMEZ, S.; GROSFOGUEL, R. (ed.). El giro decolonial: reflexiones para una diversidad epistémica más allá del capitalismo global. Bogotá: Siglo del Hombre Editores; Universidad Central, Instituto de Estudios Sociales Contemporáneos y Pontificia Universidad Javeriana, Instituto Pensar, 2007. p. 115-142. 